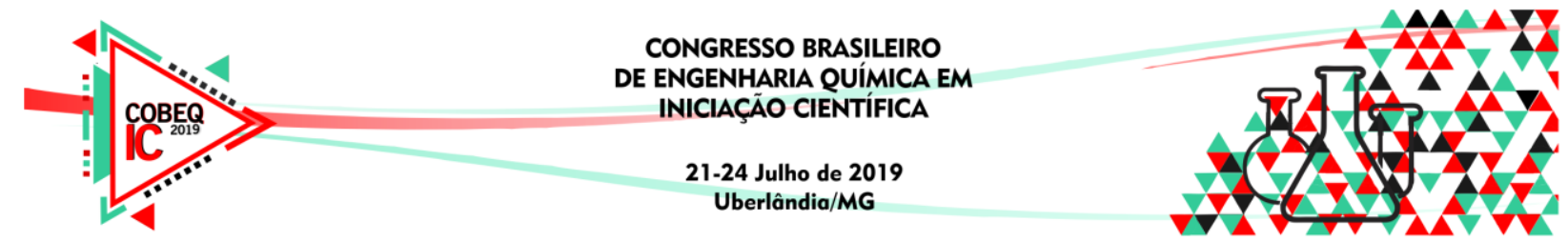

\title{
ESTUDO DO EFEITO DE NANOPARTÍCULAS DE OURO INCORPORADAS EM CATALISADORES DE DIÓXIDO DE TITÂNIO SINTETIZADOS ATRAVÉS DO PROCESSO SOL- GEL
}

\author{
I. B. P. FERREIRA ${ }^{1}$ e C. D. R. de SOUZA ${ }^{1}$ \\ ${ }^{1}$ Universidade Federal do Amazonas, Departamento de Engenharia Química \\ E-mail para: iagopacheco.ib@gmail.com
}

\begin{abstract}
RESUMO - Os nanomateriais decorrem da possibilidade de terem suas propriedades físicas e químicas moduladas em função da distribuição de tamanho e geometria das nanopartículas. Estes podem ser incorporados aos materiais a fim de melhorar ou conferir novas propriedades. Em particular, nanopartículas metálicas exibem propriedades óticas extremamente interessantes. Logo, este trabalho teve como objetivo verificar a interação entre nanopartículas de ouro com catalisadores de $\mathrm{TiO}_{2}$ sintetizado pelo método sol-gel em diferentes temperaturas durante o tratamento térmico, para testes posteriores na aplicação e eficiência na atividade fotocatalítica na região do visível. As nanopartículas de ouro (AuNPs) foram incorporadas ao $\mathrm{TiO}_{2}$, utilizando como precursor o isopróxido de titânio pelo método sol-gel, calcinado à $400^{\circ} \mathrm{C}, 600^{\circ} \mathrm{C}$ e $800^{\circ} \mathrm{C}$. As caracterizações do complexo AuNP-TiO ${ }_{2}$ foram feitas pelas análises de DRX, UV-Vis, MEV, EDS e FRX. Grupos nanoestruturados foram obtidos conforme o aumento da temperatura no tratamento térmico, além disso o tamanho das AuNPs diminuiu até sua aparente ausência à $800^{\circ} \mathrm{C}$, apresentando menores quantidades de $\mathrm{Au}$, porém ocorreu um aumento no tamanho da partícula do semicondutor, e também no teor de titânio. Portanto, o método de síntese e o tratamento térmico são parâmetros que possuem grande influência na obtenção deste catalisador. A temperatura do tratamento térmico mais pertinente a aplicações fotocatalíticas observada foi a $600^{\circ} \mathrm{C}$ devido as suas características, como maior teor de ouro, além de uma morfologia nanoestruturada mais interessante a aplicações.
\end{abstract}

\section{INTRODUÇÃO}

A possibilidade de projetar materiais com propriedades pré-estabelecidas é decorrente da nanoescala, sendo a base das diversas aplicações dos nanomateriais (Peters et al, 2016). Assim, o controle do tamanho das partículas e a modificação da superfície permitem o uso extensivo de nanopartículas de ouro (AuNPs) em tecnologias avançadas, como aplicações biológicas, condutores eletrônicos e catálise (Han Lee et al., 2017), isto devido ao fato do seu comportamento catalítico e também por sua alta seletividade em reações. As propriedades ópticas de nanopartículas metálicas surgem da interação da luz com nanoestruturas de dimensões menores que o seu comprimento (Marangoni et al., 2013). AuNPs mostram absorções bem definidas em regiões do espectro visível, denominadas de banda plasmon ressonante, com picos acentuados ( $\left.\lambda_{\text {máx }}\right)$ na faixa de 530 nanômetros. 


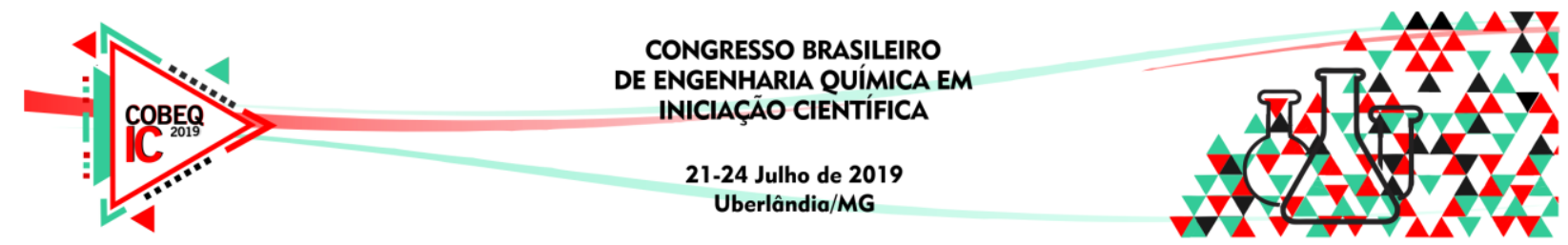

Por sua vez, o dióxido de titânio $\left(\mathrm{TiO}_{2}\right)$, ou titânia, é um material versátil, que apresenta propriedades interessantes, como sua baixa reatividade química e semicondutância fotossensível. Para a obtenção deste óxido existem vários métodos, um deles é o processo solgel, técnica amplamente utilizada por ser ambientalmente viável, de baixo custo e que possibilita a obtenção de pós em escala nanométrica com homogeneidade química satisfatória e alta pureza em baixas temperaturas. O método baseia-se no preparo e manipulação controlada de suspenções coloidais, onde ocorrem as reações de hidrólise e condensação do precursor para a formação de partículas de tamanho coloidal (sol) e posteriormente formação da rede tridimensional (gel) (Braga, 2014).

Por apresentar diversas vantagens, este semicondutor possui um amplo campo de aplicações, sendo bastante estudado e utilizado no processo de fotocatálise heterogênea, devido ao seu custo e eficiência. Suas propriedades fotocatalíticas são derivadas da formação de portadores de cargas fotogeradas (lacuna e elétron) que ocorre após a absorção da luz em diferentes espectros, porém, correspondendo a banda de gap (Srikanth et al., 2017). Porém este semicondutor possui pequena fotoatividade na faixa do visível, restringindo apenas a faixa UV, de modo que a luz UV está em apenas 3-5\% da luz solar total incidente, e a luz visível em quase 45\% (Gogoi et al., 2017).

A realização de dopagem neste semicondutor com metais, como o ouro citado anteriormente, abre a possibilidade de mudar a estrutura eletrônica das nanopartículas de $\mathrm{TiO}_{2}$, alterando sua composição química e propriedades ópticas, fazendo com que seja possível aplicá-lo diretamente em funções específicas. (Anton et al., 2015).

Portanto, o presente estudo tem como finalidade verificar a interação entre nanoparticulas de ouro associadas a catalisadores de $\mathrm{TiO}_{2}$ sintetizados pelo método sol-gel em diferentes tempertaruras de calcinação, para testes posteriores na aplicação e verificação da eficiência na atividade fotocatalítica na região do visível.

\section{METODOLOGIA}

As nanopartículas de ouro foram preparadas pela redução do ácido cloroáurico com citrato de sódio. Foram utilizados $20 \mathrm{~mL}$ de solução do ácido $(35: 100)$ e $5 \mathrm{~mL}$ de solução de citrato de sódio (1:25), deixados em refluxo em um balão de 3 bocas por 60 minutos, para reação e formação de AuNPs. A síntese do $\mathrm{TiO}_{2}$ foi realizada pelo método sol-gel, com razão volumétrica do isopropóxido de titânio, água deionizada e etanol mantidos a 6:10:100.

Primeiramente, foi utilizado álcool etílico para hidrolisar isopropóxido de titânio em temperatura ambiente, seguida da adição de água deionizada sob agitação contínua durante 1 hora. Posteriormente adicionou-se a solução coloidal de ouro preparada anteriormente, deixando em agitação por mais 1 hora para que ocorresse hidrólise e condensação dos componentes. A solução resultante foi deixada em repouso por 24 horas para processo de nucleação. Em seguida, o material foi submetido a secagem $\left(75^{\circ} \mathrm{C}\right)$ por 12 horas em estufa para obtenção do gel seco, finalizando então com o tratamento térmico, calcinado à $400^{\circ} \mathrm{C}$, $600^{\circ} \mathrm{C}$ e $800^{\circ} \mathrm{C}$.

O material foi caracterizado em um Difratômetro de Raios-X pelo equipamento X-Ray Diffractometrer Lab X, modelo XDR-6000, marca Shimadzu, com radiação CuKa. As 


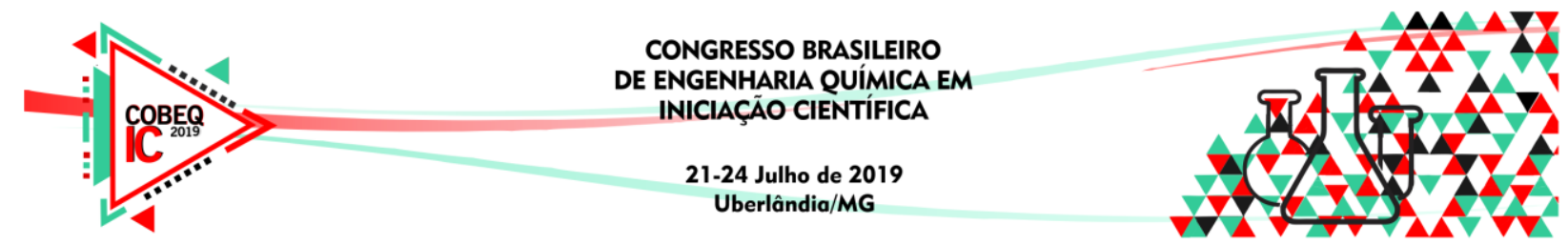

amostras foram escaneadas na faixa $2 \theta$ de $20^{\circ}$ a $60^{\circ}$, velocidade de $2^{\circ} /$ minuto, voltagem de 40 $\mathrm{kV}$ e corrente de $30 \mathrm{~mA}$. Os ensaios de MEV e EDS foram realizados pelo equipamento de modelo Quanta 250 e marca Fei Company. As análises de UV-Vis foram executadas em um espectrofotômetro modelo Global Trade Technology, em cubetas de quartzo, com caminho ótico de $1 \mathrm{~cm}$. As análises de FRX foram realizadas em equipamento da marca Panalytical modelo Epsilon 3-X, com tensão máxima de $50 \mathrm{kV}$, corrente máxima de $3 \mathrm{~mA}$ e gás hélio (pressão $10 \mathrm{~atm} . / 10 \mathrm{kgf} / \mathrm{cm}^{2}$ ).

\section{RESULTADOS E DISCUSSÃO}

\subsection{Espectroscopia de absorção região do ultravioleta e visível (UV/Vis)}

A análise de UV/Vis foi realizada para identificação de nanopartículas de ouro no catalisador, por meio da presença da banda plasmon ressonante característica. Nota-se pela Figura 1, um $\lambda_{\text {máx }}$ em $530 \mathrm{~nm}$ para os catalisadores sinterizados a $400^{\circ} \mathrm{C}$ e $600^{\circ} \mathrm{C}$, identificando presença de AuNPs com tamanho médio acima de 40 nanômetros, como descrevem Zhang et al. (2014), tamanho característico para esta faixa, onde a $600^{\circ} \mathrm{C}$ ocorreu uma forte banda de absorção com pico bastante acentuado. Porém é possível observar que o catalisador tratado a $800^{\circ} \mathrm{C}$ não houve formação de AuNP aparente. Os autores citam que as nanopartículas são termodinamicamente instáveis, principalmente devido a sua superfície de contato, assim a elevada temperatura durante o tratamento térmico pode ter ocasionado deficiência na formação destas nanopartículas metálicas.

Figura 1 - Espectros de UV/Vis para catalisadores $\mathrm{Au}+\mathrm{TiO}_{2}$ calcinados à $400^{\circ} \mathrm{C}, 600^{\circ} \mathrm{C} \mathrm{e}$ $800^{\circ} \mathrm{C}$.

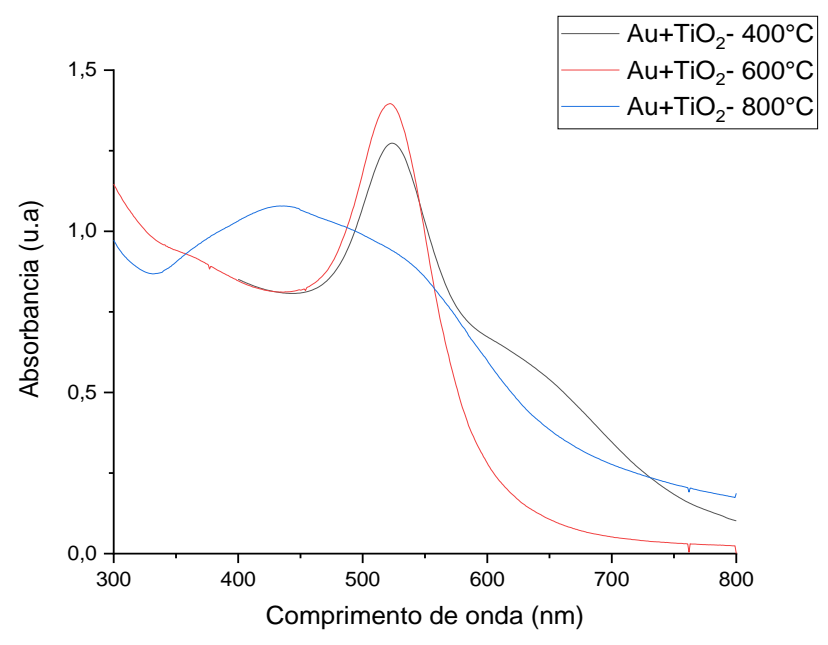

\subsection{Difração de Raios-X (DRX)}

A partir da caracterização estrutural das nanopartículas de $\mathrm{Au}+\mathrm{TiO}_{2}$ por $\mathrm{DRX}$, foi obtido o difratograma exibido na Figura 2. É possível notar que na amostra a $400^{\circ} \mathrm{C}$, ocorreu formação de apenas duas fases cristalinas, cujos picos de difração correspondentes estão identificados no espectro de difração, anatase, a estrutura mais estável, e bruquita, estrutura presente em baixas temperaturas, características citadas pelos autores Anton et al. (2015). 


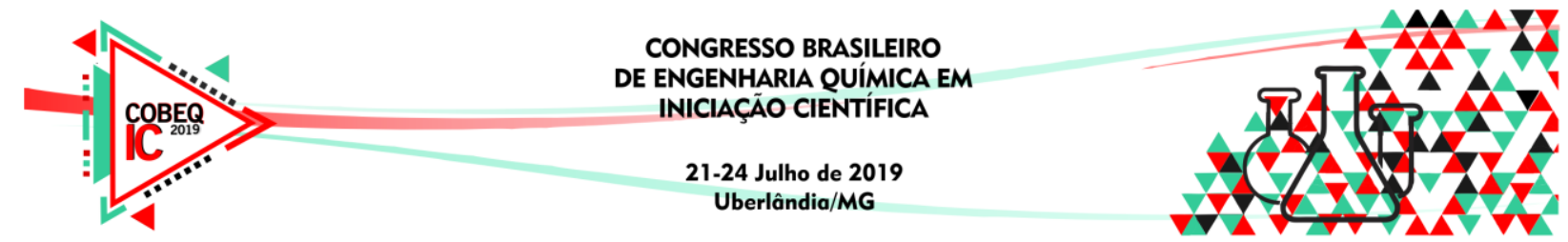

Figura 2 - DRX para amostras a diferentes temperaturas. Sendo, R - rutilo, A - anatásio e B bruquita.

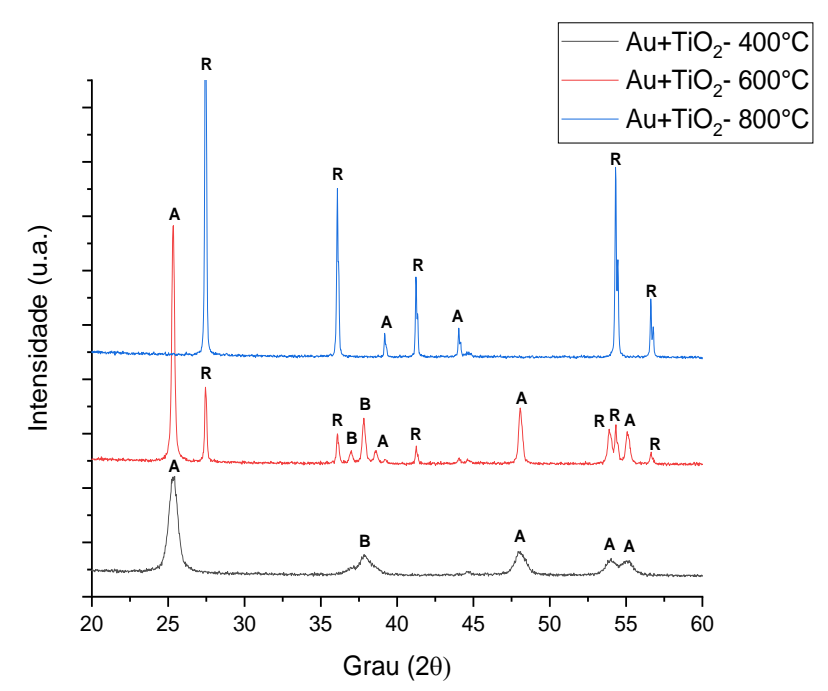

Para a amostra processada a $600^{\circ} \mathrm{C}$, destaca-se a formação predominante da fase cristalina anatase, enquanto que a fase bruquita ocorre em menor intensidade, o que se encontra de acordo com Shalimar et al. (2016), pois nessa faixa de temperatura ocorre transição das fases anatase e bruquita para rutilo. Pode-se também observar que os picos de difração mostraram considerável alargamento, indicando, assim, a característica nanométrica das partículas do pó de $\mathrm{Au}-\mathrm{TiO}_{2}$. O tamanho de cristalito médio calculado pela equação de Scherrer foi de $13,10 \mathrm{~nm}, 21,50 \mathrm{~nm}$ e $37,80 \mathrm{~nm}$, à $400^{\circ} \mathrm{C}, 600^{\circ} \mathrm{C}$ e $800^{\circ} \mathrm{C}$, respectivamente.

\subsection{Microscopia Eletrônica de Varredura (MEV)}

Com os ensaios de Microscopia de Eletrônica de Varredura, mostrados na Figura 3, foi possível visualizar a imagem estrutural das amostras, que apresentaram morfologia nanoestruturada, assim como observa-se também a formação de aglomerados de partículas de aproximadamente $1 \mu \mathrm{m}$, o que propõe o tamanho de partícula na escala nanométrica.

Figura 3 - MEV das amostras do catalisador calcinados a $400^{\circ} \mathrm{C}, 600^{\circ} \mathrm{C}$ e $800^{\circ} \mathrm{C}$ respectivamente. Com o aumento de 1000 x e 10000 x.

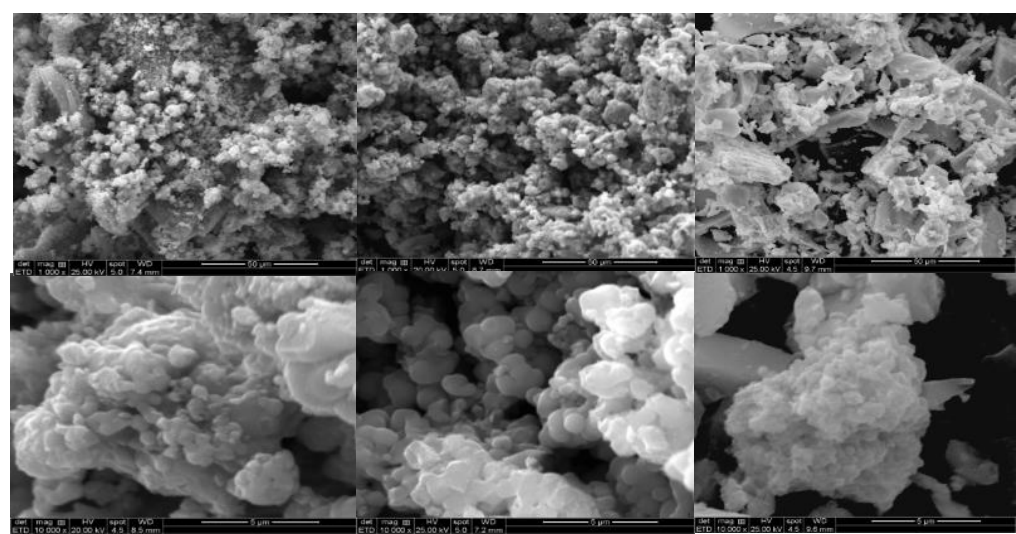




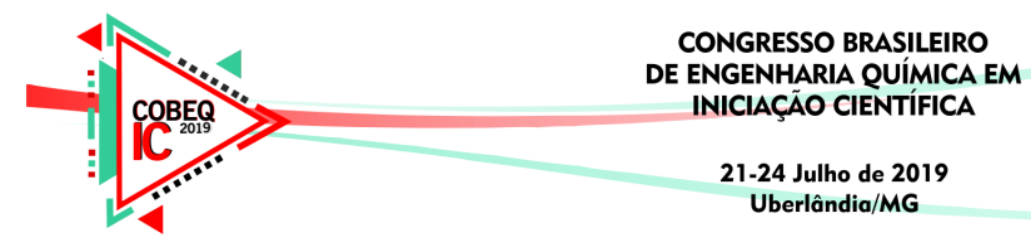

É possível constatar que com o aumento da temperatura de sinterização o catalisador passa de uma estrutura mais compactada e formações cristalinas mais estruturadas, porém conglomerada, para uma estrutura maior e posteriormente mais densa com alguns pequenos filamentos variados e formas heterogêneas.

\subsection{Espectroscopia por energia dispersiva de Raios X (EDS)}

A Tabela 4 exibe a análise de espectroscopia dispersiva de Raios- $\mathrm{X}$ das áreas selecionadas dos três catalisadores sintetizados, confirmando que as amostras possuem teor de ouro em sua composição elementar. Salienta-se que para $\mathrm{Au}-\mathrm{TiO}_{2}$ a $600^{\circ} \mathrm{C}$ apresentou uma maior quantidade de ouro, além da presença de outros elementos, enquanto que no catalisador sinterizado a $800^{\circ} \mathrm{C}$, apresentou menor quantidade. Vale destacar a presença de outros elementos em baixas quantidades como o fosforo presente nas três amostras, alumínio nas amostras calcinadas a $600^{\circ} \mathrm{C}$ e $800^{\circ} \mathrm{C}$, e silício apenas na amostra $\mathrm{Au}-\mathrm{TiO}_{2}$ a $600^{\circ} \mathrm{C}$. Isto se deve pelo fato da análise de EDS ser realizada em determinados pontos da amostra, o que é possível que ocorra algumas variações. Outra informação importante é o teor de titânio, que aumenta com o aumento da temperatura durante o tratamento térmico.

Tabela 1 - Composição das amostras analisadas em diferentes pontos nas análises de EDS.

\begin{tabular}{|c|c|c|c|c|c|c|}
\hline Amostra & $\mathrm{Ti}(\%)$ & $\mathrm{O}(\%)$ & $\mathrm{Au}(\%)$ & $\mathrm{Si}(\%)$ & $\mathrm{P}(\%)$ & $\mathrm{Al}(\%)$ \\
\hline \hline $\mathrm{Au}-\mathrm{TiO}_{2}$ a $400^{\circ} \mathrm{C}$ & 45,22 & 49,74 & 5,03 & - & 0,01 & - \\
\hline $\mathrm{Au}-\mathrm{TiO}_{2}$ a $600^{\circ} \mathrm{C}$ & 47,06 & 42,64 & 10,21 & 0,03 & 0,04 & 0,02 \\
\hline $\mathrm{Au}-\mathrm{TiO}_{2}$ a $800^{\circ} \mathrm{C}$ & 50,39 & 47,05 & 2,48 & - & 0,05 & 0,03 \\
\hline
\end{tabular}

\subsection{Fluorescência de Raios-X (FRX)}

Os ensaios de FRX foram realizados para proporcionar informação da composição das amostras mais precisamente através da técnica, como mostrado na Tabela 2. Atenta-se que o maior teor de ouro se encontra na amostra 2 , tratada a $600^{\circ} \mathrm{C}$, em contrapartida, a amostra 3 exibiu menor quantidade, corroborando com a análise de EDS realizada. Houve formação de outros óxidos em baixas quantidades, como a alumina $\left(\mathrm{Al}_{2} \mathrm{O}_{3}\right)$ e óxido de ferro apenas para a amostra $\mathrm{Au}-\mathrm{TiO} 2$ a $600^{\circ} \mathrm{C}$, pois durante o tratamento térmico ocasiona a aparição destes componentes.

Tabela 2. Composição química dos catalisadores calcinados nas três diferentes temperaturas.

\begin{tabular}{|c|c|c|c|c|c|c|c|c|}
\hline Amostra & $\mathrm{TiO}(\%)$ & $\mathrm{Au}(\%)$ & $\mathrm{P}_{2} \mathrm{O}_{5}(\%)$ & $\mathrm{Al}_{2} \mathrm{O}_{3}(\%)$ & $\mathrm{Fe}_{2} \mathrm{O}_{3}(\%)$ & $\mathrm{CaO}(\%)$ & $\operatorname{Ag}(\%)$ & Demais (\%) \\
\hline$\overline{\mathrm{Auu}-\mathrm{TiO}_{2} \text { a } 400^{\circ} \mathrm{C}}$ & 92,328 & 6,86 & 0,487 & 0,016 & $\overline{0}$ & 0,142 & 0,120 & 0,047 \\
\hline $\mathrm{Au}-\mathrm{TiO}_{2}$ a $600^{\circ} \mathrm{C}$ & 87,253 & 12,03 & 0,389 & 0,032 & 0,007 & 0,143 & 0,119 & 0,027 \\
\hline $\mathrm{Au}-\mathrm{TiO}_{2}$ a $800^{\circ} \mathrm{C}$ & 96,144 & 3,14 & 0,396 & 0,020 & 0 & 0,145 & 0,121 & 0,034 \\
\hline
\end{tabular}




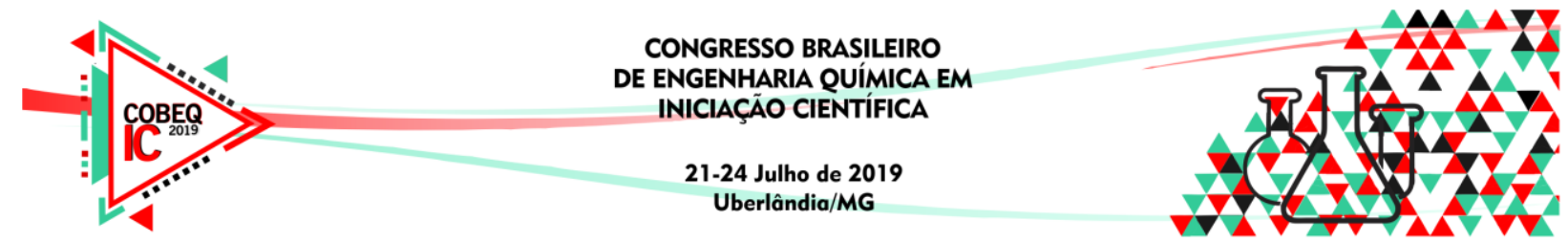

\section{CONCLUSÕES}

A partir das caracterizações realizadas, o complexo $\mathrm{Au}-\mathrm{TiO}_{2}$ sintetizado pelo método sol-gel mostrou que a variação de temperatura do processo de calcinação foi o parâmetro determinante na obtenção da fase cristalina, o que consequentemente afetou outros parâmetros como o tamanho das partículas e a estrutura do material. Foi possível verificar que com o aumento da temperatura, a quantidade de titânio aumentou, isto devido a mudança e transformação das fases cristalinas, bem como, as nanopartículas mostram tendência de aglomeração fazendo com que ocorram mudanças nas suas características. Com os ensaios de composição do catalisador, notou-se uma variação nos teores de ouro e de titânio, principalmente em temperaturas mais elevadas. $\mathrm{O}$ catalisador $\mathrm{Au}-\mathrm{TiO}_{2}$ a $600^{\circ} \mathrm{C}$ apresentou maior teor de ouro, além de uma morfologia nanoestruturada mais interessante a aplicações.

Portando, a partir dos resultados obtidos, pretende-se dar continuidade nos estudos deste catalisador produzido para realização de testes em processos fotocatalíticos para degradação de poluentes orgânicos por meio de luz solar.

\section{REFERENCIAS}

ANTON, L. B.; BRAGA, N. A. Nanoparticulas de $\mathrm{TiO}_{2}$ : síntese pelo método sol-gel e técnicas de caracterização. Scientia Amazonia. n.7, p. 36-59, 2015.

BRAGA, A. N. S., et al. Síntese de mulita pelo processo sol-gel: Uma revisão da literatura. Revista Eletrônica de Materiais e Processos, v. 9, n. 2, p. 60 - 73, 2014.

GOGOI, N.; BORAH, G.; GOGOI, P. K.; CHETIA, T. R. TiO 2 supported gold nanoparticles: an efficient photocatalyst for oxidation of alcohol to aldehyde and ketone in presence of visible light irradiation. Chemical Physics Letters. v. 692, p. 224-231. 2017

HAN LEE, S.; JUNG, H. K.; KIM, T. C. Facile method for the synthesis of gold nanoparticles using an ion coater. Yongin, Republic of Korea. Applied Surface Science. v. 434, p. 1001-1006, 2017.

MARANGONI, V. S.; PAINO, I. M.; ZUCOLOTTO, V. Synthesis and characterization of jacalin-gold nanoparticles conjugates as specific markers for cancer cells. Colloids and Surfaces B: Biointerfaces, v.112, p.380-386, 2013.

PETERS, R.J.B.; BOUWMEESTER, H.; GOTTARDO, S.; AMENTA, V.; ARENA, M.; BRANDHOFF, P.; MARVIN, H.J.P.; MECH, A.; BOTELHO MONIZ, F.; PESUDO, L.Q.; RAUSCHER, H.; SCHOONJANS, R.; UNDAS, A.K.; VETTORI, M.V.; WEIGEL, S.; ASCHBERGER, K.; Nanomaterials for products and application in agriculture, feed and food. Trends Food Sci. Technol. vol. 54. 2016.

SHALIMAR, S. B.; XAVIER, L. P. S.; SILVA, A. C.; AQUINO, S. F. Imobilização de dióxido de titânio em diferentes materiais suporte para o emprego em fotocatálise heterogênea. Química Nova. Vol. 39 (7), p. 836-844. 2016.

SRIKANTH, B.; GOUTHAM, R.; NARAYAN, R. B.; RAMPRASATH, A.; GOPINATH, K. P.; SANKARANARAYANAN, A. R. Recent advancements in supporting materials for immobilised photocatalytic applications in waste water treatment. TN, Índia. Journal of Environmental Management, v. 200, p. 60-78, 2017.

ZHANG, Y.; CHU, W.; FOROUSHANI, A.D.; WANG, H.; LI, D.; LIU, J.; BARROW, C.J.; WANG, X.; YANG, W. New gold nanostructures for sensor applications: a review, Materials Basel. v.7, 5169-5201. 2014. 